\title{
Hydrogen production by coupling pressurized high temperature electrolyser with solar tower technology
}

\author{
N. Monnerie ${ }^{1 *}$, A. Houaijia ${ }^{1}$, M. Roeb ${ }^{1}$ and C. Sattler ${ }^{1}$ \\ ${ }^{1}$ German Aerospace Center (DLR), Institute of Solar Researche, \\ Linder Höhe, 51147 Cologne, Germany \\ (*) nathalie.monnerie@dlr.de
}

Solar hydrogen production by coupling pressurized high temperature electrolyser with concentrated solar tower technology is studied. As the high temperature electrolyser needs constant temperature operation conditions, the focus is made on the molten salt solar tower due to its high storage capacity. Flow sheet has been elaborated and simulations have been carried out with the software Aspen Plus 8.4 for MW scaled-up hydrogen production plants. The solar part has been laid out with the software HFLCAL. Two different scenarios have been considered: the first one concerns the production of $400 \mathrm{~kg} / \mathrm{d}$ hydrogen corresponding to a mobility scenario. The second scenario deals with the production of $4000 \mathrm{~kg} / \mathrm{d}$ hydrogen for an industrial use. The process has been analyzed from a thermodynamic point of view by calculating the overall process efficiency. Taking into account the storage and a steam to hydrogen conversion of $50 \%$, the process efficiency was calculated at $14 \%$ and the solar efficiency at $59.2 \%$.

\section{Presentation of the technology}

In the frame of the FCH-JU project SOPHIA, a pressurized high temperature electrolyser is developed for coupling with concentrated solar energy. The total energy demand of the electrolyser unit consists indeed of electricity and heat which can be both generated by solar concentrating energy systems. The combination of hydrogen production by high temperature electrolysis and concentrated solar thermal energy is very attractive since this will create a symbiosis with much profit for both technologies. The solar tower technology is a large scale technology which utilizes many large, computer controlled, sun-tracking mirrors, so called heliostats, to focus sunlight on a receiver at the top of a tower. This receiver transforms the solar radiation into heat. A heat transfer fluid heated in the receiver absorbs indeed the highly concentrated radiation reflected by the heliostats and converts it into thermal energy. This heat can be coupled to any heat driven process, i.e. for electricity generation or for driving chemical reactions. This technology enables operation at high temperature level and provides heat storage capacities. Solar towers typically stand about 75-150 m height [1]. These plants are best suited for utility-scale applications in the 10 to 200 MWe range [2]. This technology has high net solar to electrical efficiency and is commercially proven. Being given the boundary conditions of the pressurized high temperature electrolyser which needs constant heat operation conditions, the focus is made in this study on the molten salt solar tower technology which uses molten salts as heat transfer fluid and long-term molten salt thermal storage system. The high temperature electrolyser operates at $750^{\circ} \mathrm{C}$ and 15 bar. A steam to hydrogen conversion of $50 \%$ is assumed.

\section{Results}

Integration scheme of pressurized high temperature electrolyser with the solar molten salt tower has been identified and flow charts have been defined for a large-scale system. The process efficiency (related to the thermoelectrical part of the process excluding the solar part) was then calculated regarding the following formula:

$$
\eta=\frac{\dot{m}_{H_{2}} L H V_{H_{2}}}{\dot{Q}_{\text {receiver }}+\sum \dot{W}}
$$

With: $\quad$ Qreciver $_{\text {r }}$ solar heat feeding to the process

$$
\Sigma_{\mathrm{w}}=\text { sum of the power of the electrical heaters, pumps... }
$$

With the made assumptions, the process efficiency is about 14\%. The solar part of the process consisting in heliostat field, tower and solar receiver was dimensioned and optimized for the molten salt solar tower for a plant located in Almeria, Spain. Storage is implemented in order to keep hot the high temperature electrolyser night and day.

The annual average solar efficiency $\eta \mathrm{s}$ is defined as the net thermal power $P_{\text {th }}$ (i.e. including its thermal and optical losses) that can be used for heating the fluids in the receiver and for the chemical reaction divided by the theoretical maximum of solar radiation impinging on the mirror surfaces $\left(A_{\text {mirror }}\right)$ : 
$\eta_{s}=\frac{\int_{t=0}^{T M Y} P_{t h}(t) \cdot d t}{A_{\text {mirrors }} \cdot \int_{t=0}^{T M Y} D N I(t) \cdot d t}$

This efficiency has been calculated for the two scenarios studied. Table 1 shows the results obtained for plants producing $400 \mathrm{~kg} / \mathrm{d}$ hydrogen and $4000 \mathrm{~kg} / \mathrm{d}$ hydrogen (annual average daily production). With the integration of the storage system in a plant having an annual average daily production of $400 \mathrm{~kg} / \mathrm{d}$ hydrogen, the heliostat field consists of 198 heliostats with a reflective surface of $121.34 \mathrm{~m}^{2}$ each. The total heliostat surface is about $24025 \mathrm{~m}^{2}$. The tower has a height of $125 \mathrm{~m}$ and the solar receiver an aperture of $24 \mathrm{~m}^{2}$. It results in an annual average solar efficiency of $59.2 \%$.

\begin{tabular}{|c|c|c|}
\hline & $\mathbf{4 0 0} \mathbf{~ k g} / \mathbf{d ~ \mathbf { H } _ { \mathbf { 2 } }}$ & $\mathbf{4 0 0 0} \mathbf{~ k g} / \mathbf{d ~ \mathbf { H } _ { \mathbf { 2 } }}$ \\
\hline Annual average receiver power [MW] & 14 & 138 \\
\hline Tower height [m] & 125 & 200 \\
\hline Number of heliostat & 198 & 2102 \\
\hline Receiver aperture $\left[\mathbf{m}^{\mathbf{2}}\right]$ & 24.15 & 192.85 \\
\hline Annual average solar efficiency [\%] & 59.2 & 56.8 \\
\hline
\end{tabular}

Table 1. Lay out of the heliostat filed for coupling with molten salt solar tower

Figure 1 shows the disposition of heliostat filed in the case of an annual average daily production of $400 \mathrm{~kg} / \mathrm{d}$ hydrogen.

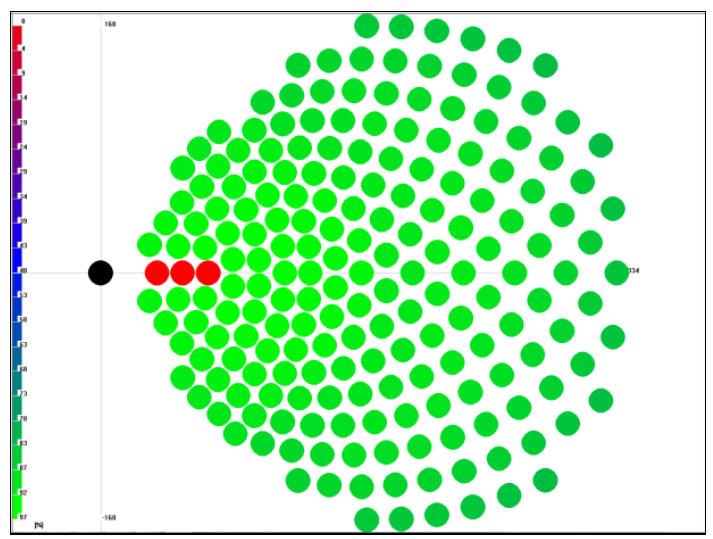

Figure 1. Heliostat field for the molten salt solar tower with an annual average receiver power of 14 MW featuring 198 heliostats.

\section{Conclusion}

The solar tower technology working with molten salt as fluid enable to provide the high temperature electrolyser with stable conditions thanks to long-term thermal molten salt storage system that is normally integrated in these kinds of plants. The process efficiency is calculated at $14 \%$ and the solar efficiency at $56.8 \%$ to $59.2 \%$ depending of the scale of the hydrogen production plant.

\section{Acknowledgments}

The authors of this paper gratefully acknowledge the co-funding of the project SOPHIA (Grant agreement No. 621173) by the FCH JU.

\section{References}

[1] Barlev, D., R. Vidu, and P. Stroeve, Innovation in concentrated solar power. Solar Energy Materials and Solar Cells, 2011. 95(10): p. 2703-2725.

[2] Romero, M. and A. Steinfeld, Concentrating solar thermal power and thermochemical fuels. Energy \& Environmental Science, 2012. 5(11): p. 9234-9245. 